\title{
A novel network-based analysis to measure efficiency in science and technology parks: The ISA framework approach
}

\author{
M. Pilar Latorre ${ }^{a}$, Ramón Hermoso ${ }^{b}$, María A. Rubio ${ }^{c}$ \\ ${ }^{a}$ Deparment of Business \& Administration, Univesity of Zaragoza, Spain \\ ${ }^{b}$ Deparment of Department of Informatics and Systems Engineering, Univesity of Zaragoza, Spain \\ c Defense University Center, Univesity of Zaragoza, Spain \\ \{latorrep, rhermoso, marubio\}@unizar.es
}

\section{Corresponding author:}

Dr. María A. Rubio

Centro Universitario de la Defensa, Ctra. Huesca, s/n 50090 Zaragoza (Spain)

e-mail:marubio@unizar.es

Phone: +34 976739876

DOI 10.1007/s10961-017-9585-9 


\title{
A novel network-based analysis to measure efficiency in science and technology parks: The ISA framework approach
}

\begin{abstract}
In the last years Science and Technology Parks (STPs) have been considered facilitators of interorganizational relationships, as well as instruments of public policy, by creating networks and allowing access for the learning of local innovation. In this study, we propose a quantitative tool as support for measuring the efficiency of STPs through the analysis of the complex networks they form. We present a generic framework called the Inter-Relationship Science-Park Analysis (ISA) framework to study STPs at three different levels of management: i) individual entities (research centres, universities, innovation companies, etc.); ii) STP global management; and iii) productive sector development. Moreover, we have applied the ISA framework to a real world case study: the Walqa Science and Technology Park. Through it we have been able to know what relationships are established within this Science and Technology Park and which are the most important nodes in this network of interactions.
\end{abstract}

Keywords

Science and technology parks; Innovation; Complex networks; Inter-organizational networks $J E L$

O32. Management of Technological Innovation and R\&D 


\section{INTRODUCTION}

Innovation is particularly important for technology-based firms. The ability of the firm to create new knowledge and exploit it (its ability to learn and innovate) is a key determinant for its long-term success. Their own resources and capabilities are important, but relationships with other companies can become more influential in the process of learning and innovation. Because learning is a key resource accumulation mechanism in knowledge-intensive industry sectors, the ability of firms to exploit resources through network relationships is crucial for their survival (Autio, Sapienza, \& Almeida, 2000).

Companies look for explicit or non-explicit alliances with other organizations in their near environment to guarantee resources for innovation. Companies are interested in sharing resources because they can learn from the experiences and ways of doing of others and incorporate best practices. Furthermore, they can access new information and new knowledge that may turn into new ideas and business opportunities (Tsai, 2000).

The creation of territories which may become chambers of commerce, venture capital companies, universities and research centers, etc., to support micro enterprises and small and medium-sized enterprises (SMEs) - in some cases they also involve large companies - in productive concentrations in the territory. These organizations are involved at various stages of the process, facilitating cooperation and decision making, as well as promoting regional innovation systems (Aydalot, 1986; Basile, 2011; Hodgson, 1996).

For a few decades, science and technology parks (STPs) innovation areas requires coordination between various actors, including local governments, have been considered facilitators of interorganizational relationships, in which policies and actors are integrated within configurations that take leading roles in all developed countries. Thus, with the ultimate goal of promoting local economic development and technological modernization in the regions, STPs have become instruments of public policy by creating networks and allowing access for the learning of local innovation. In other words, inter-organizational relationships in STPs integrate local scientific, technical and social skills to enhance the productive use of knowledge and the dissemination of innovations (Castells \& Hall, 1994).

There is a considerable number of studies on the relationships between entities in STPs (Löfsten \& Lindelöf, 2002; Phillimore, 1999; Vedovello, 1997). Most of these works focus on particular ad hoc relationships between entities, such as innovation companies and universities (Bakouros, Mardas, \& Varsakelis, 2002; Fukugawa, 2006). A few other works have analyzed and compared the types of 
relationships between those companies established in STPs in contrast to those established in other industrial areas (A. Link \& Scott, 2003; Löfsten \& Lindelöf, 2002). However, in these works, the methodology applied to obtain conclusions is based on statistical analysis of data collected from surveys. That is, the conclusions are derived from the analysis of responses to those surveys by the entities involved. We claim that although these studies have brought about some important advances in gaining a better understanding of the functioning of STPs, they have not addressed the problem of providing more complex mechanisms to analyze the relationships in STPs. New approaches are needed that are capable of analyzing STPs from three different perspectives: i) individual entities (research centers, universities, innovation companies, etc.); ii) STP global management; and iii) productive sector development. In this paper we propose a two-stage process: on the one hand we gather descriptive information about the STP functioning through the use of surveys. Once these data have been collected a network-based analysis approach is carried out in order to better understand the relationships in the STP (see Fig. 1).

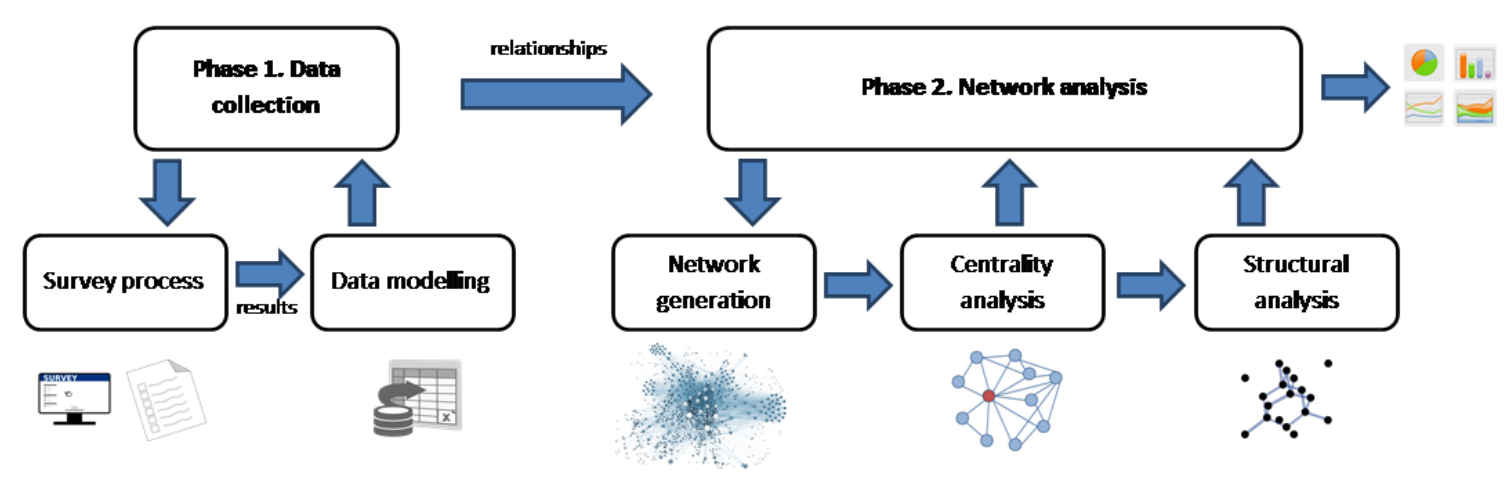

Figure 1. Two-stage flow for STP analysis

STPs can be viewed as networks of entities linked by any type of relationship held among participants. Over the last few years, the study of complex networks has resulted in considerable progress in numerous fields, such as physics, medicine, computer science, etc. Much of this research focuses on the evaluation of relationships between nodes and attempts to unveil their relevance in the environment. This evaluation can be carried out using different methods: from studying the centrality of nodes to the analysis of the structure of the network. As a result, interesting properties can be derived, such as the relative importance of nodes in the network or the communities that emerge throughout its evolution. 
With this in mind, we present a generic framework to study STPs from the three perspectives described above. We call this the Inter-Relationship Science-Technology Park Analysis (ISA) framework and it is based on the analysis of networks generated from the inter-entity relationships that emerge in STPs. That is, modelling STPs as networks allows us to analyze the centrality (and in turn the importance) of the entities participating in the STPs and to extract some structural features. To show the value of this tool, we employ it to analyze a particular STP, Walqa (Huesca, Spain). The output of the ISA framework is used to provide important estimates for further management in relation to the three perspectives presented: management of the individual entity, global STP management and productive sector management (e.g. clustering differentiation).

The rest of the paper is structured as follows: in Section 2 and 3 we review the existing literature on the topic. Then, in Section 4 we present the ISA framework. We apply the framework to a real-world case study, the Walqa STP, in Section 5. Section 6 discusses the findings with references to related work in the field. Finally, we summarize our conclusions and present suggestions for future work in Section 7.

\section{INTER-ORGANIZATIONAL RELATIONSHIPS AS THE KEY TO INNOVATION}

Innovation is essential to ensure the competitiveness of companies. However, in many cases, the small size of companies makes it more difficult for them to access all the intangible assets that enable innovation; the choices that companies make to access internal and external sources of creation and the transmission of knowledge will be crucial to their success in the long term. The theory of resources and capabilities has ignored one of the basic assumptions of industrial organization, namely that resources can be exchanged at no cost between businesses and often at no charge (Autio et al., 2000).

Companies are heterogeneous organizations equipped with different capacities and resources related to their characteristics (size, type, etc.) and the sector in which they operate. In the search for competitive advantage (Porter, 1985), relationships that are established between companies are a cornerstone for individual strategy because they provide access to skills and resources that would otherwise be difficult to reach. A wide variety of links with other organizations mainly involve intangible resources. These links represent the exchange of a great variety of information, knowledge and other forms of social capital (Bosma, van Praag, Thurik, \& de Wit, 2004; Gronum, Verreynne, \& Kastelle, 2012; Koka \& Prescott, 2002; Nahapiet \& Ghoshal, 1998) which the company does not have per se. The sharing of resources enables companies to achieve economies of scope and to have a major influence on the generation of 
competitive advantage. This exchange can also occur outside market channels because companies share generally similar values and common languages that can facilitate communication in the exchange process (Tsai, 2000).

Inter-organizational relationships tend to be organized around a topic or area of common knowledge, so that all companies share terminology and basic knowledge, allowing incremental learning within the network (Lesser \& Prusak, 1999).

When these companies use and generate high technology in their production processes, the need for exchange becomes even more apparent. They are typically small firms employing some staff and producing goods and services with high added value, since their work focuses on the design, development and production of products and innovative manufacturing processes by applying technical and scientific knowledge.

These types of companies usually need a link with universities or research centers, as they share areas of expertise and established relationships can encourage their development and technological upgrading (Cebrián Tarrasón, Vidal, Salmerón, Bertolín, \& Negre, 2011; Albert N. Link \& Siegel, 2007; Ponds, Oort, \& Frenken, 2009; Varga, Pontikakis, \& Chorafakis, 2012). They also act as transmitters of knowledge and technology to industry (Kirby \& Cox, 2006; A. N. Link \& Scott, 2007), and they are considered as the new engine of economic growth (D. B. Audretsch et al., 2002; Cheng, van Oort, Geertman, \& Hooimeijer, 2013).

The location of high-tech firms stresses the fundamental role that proximity plays in creating interorganizational relationships and in mediating the processes of knowledge creation, transmission and appropriation (B. Audretsch, 1998; Autio et al., 2000; Ponds et al., 2009; Varga et al., 2012). These interorganizational relationships can be born in a natural and spontaneous way, emerging from an environment, but they can also be stimulated by an institutional environment (Dyer \& Singh, 1998) which promotes or encourages these networks in a particular area of activity and in a specific territory.

\section{STPS AS FACILITATORS OF INTER-ORGANIZATIONAL RELATIONSHIPS}

Territory was considered one of the key elements for industrial location during the early decades of the last century. This was due to its inherent capability to offer natural and human resources, a market for products and agglomeration economies (Weber \& Pick, 1909). However, during the 1980s and 1990s 
other theories were developed, reinterpreting the relationship between territory and business and placing more emphasis on innovation processes to face competition. Concepts such as the innovative environment emerged combining the intervention of local economies on the one hand and the learning ability of companies on the other (Aydalot, 1986). These theories argue that innovation is conditioned not only by the individual capacities of enterprises, but also by the whole network of socio-economic and institutional actors and policies, resources and initiatives arising in the territory, which together form an environment suitable for the absorption of innovation and development (Maillat, 1995). In this sense, the public sector plays an essential role in creating an institutional structure in the territory which stimulates the quantity, quality and direction of the research undertaken, as well as the development of innovations that can be used by the company (Hodgson, 1996).

In order to support or even create these innovative territories, policies and actors are integrated into a new infrastructure model from a few decades ago is taking a leading role in all developed countries paper: STPs. These parks attempt to foster the industrial, economic, social and business development of the territories in which they are established.

Among the different areas of innovation, STPs are a highly-specialized type, playing a key role in the economic development of their environment. Through a dynamic and innovative mix of policies, programs, quality space and facilities and high value-added services, they: i) stimulate and manage the flow of knowledge and technology between universities and companies; ii) facilitate the communication between companies, entrepreneurs and technicians; iii) provide environments that enhance a culture of innovation, creativity and quality; iv) focus on companies and research institutions as well as on people: the entrepreneurs and 'knowledge workers'; v) facilitate the creation of new businesses via incubation and spin-off mechanisms, and accelerate the growth of small and medium size companies; vi) work in a global network that gathers many thousands of innovative companies and research institutions throughout the world, facilitating the internationalization of their resident companies.

For companies located in STPs, this should act as an intermediator or provider of business relations and R\&D. This role may even extend to a wider network of different actors: university, other companies with shared technology, corporations, Administration, other research centers, and even other STPs. (Basile, 2011; Gower \& Harris, 1994; Löfsten \& Lindelöf, 2002). In particular, universities and research centers are the most important actors in the creation and sharing of new technological knowledge through various forms of relationship: from formal contracts for research to more informal contracts and the 
transfer of workers between the world academic and industry (A. N. Link \& Scott, 2007; Löfsten \& Lindelöf, 2002, 2005; Massey, Quintas, \& Wield, 2003; Westhead \& Storey, 1995).

It is important to analyze whether the park is doing its job of intermediary in these interorganizational relationships. This requires observing the outputs of the framework presented in this paper as a result of interactions between all actors in the park.

\section{NETWORK ANALYSIS FOR STPS}

In this section, we intend to show how network analysis may be a key factor in studying the performance of STPs. We claim the advantages of using such a kind of analysis to be twofold: i) it allows a better understanding of the functioning of the STP from a global management perspective, so providing hints for future changes; ii) it may be used as resource for an individual company aiming to enhance its performance and it enables a company to study its own relations with other companies and to make comparisons with the development of other firms in the same STP.

\subsection{Network model}

Network analysis focuses on the use of different metrics with sets of entities linked to each other in some way. First, we define the sorts of networks we examine in this paper, i.e. those generated from firms and their relationships in a certain STP. Let $G=(V, E)$ be a graph in which $V$ represents the set of firms of the STP and $E$ stands for the set of links or connections between them. Let $\left(v_{i}, v_{j}\right) \in E$, with $v_{i}, v_{j} \in$ $V$, be an edge in $G$ representing any kind of business relationship among firms $v_{i}$ and $v_{j}$. Note that in this paper we only focus on undirected graphs as we assume that business relationships are bidirectional. These relationships might be of various kinds, such business partnerships, sponsorship, strategic alliances, etc., depending on the domain we address. For the purpose of this paper, we consider relationships in STPs to be bidirectional, that is, if there is $\left(v_{i}, v_{j}\right) \in E,\left(v_{j}, v_{i}\right) \in E$ necessarily also exists. Thus, the graph $G$ generated by the network is undirected.

Our approach analyses this type of network as a tool to interpret and enhance the performance of the firms established in the STP, as well as the performance of the STP from a management perspective. In the next section, we address some useful metrics to accomplish this task. 


\subsection{STP analysis using centrality network metrics}

There are many different metrics that make it possible to uncover some interesting individual behaviours and global properties in a network. We claim that in the domain we consider (STPs), centrality metrics are necessary to shed light on the importance of the position of a firm in the network generated. In other words, centrality metrics attempt to measure how well placed a firm is with regard to the other companies in the same STP. The concept of centrality encapsulates "micro" measures that allow us to compare nodes and to say something about how a given node relates to the overall network (Freeman, 1977; Jackson, 2008). We hold that a deep knowledge of the position of the firms in the context of the overlying network generated from the relationships that emerge in the STP may bring about certain benefits such as: strategy studies, STP specialization, opportunities for growth in the STP and some others. Let us now set out the different metrics we use to accomplish this task.

\section{Degree centrality}

The simplest way of measuring the position of a node in a network (henceforward we use the terms node and firm with the same meaning when referring to an entity in the network) is to consider degree centrality. This represents the number of links that a node has. Formally:

$$
D C^{v_{i}}=\frac{d\left(v_{i}\right)}{|V|-1}
$$

where $d\left(v_{i}\right)$ denotes the degree centrality of node $v_{i}$ in the network. This metric shows how well a firm is connected in terms of direct links. From an STP management perspective, we can also provide an average degree centrality value as follows:

$$
\overline{D C}=\frac{1}{n} \sum_{v_{i}} \frac{d\left(v_{i}\right)}{|V|-1}
$$

This value represents an average estimate for the number of relationships in the STP as a macro indicator of managing the performance of the STP.

Although degree centrality may be an important factor when analysing an STP network, it misses certain aspects that should be taken into account. While it denotes perfectly how well connected a firm is in the STP, it does not reflect how well positioned it is within the network, i.e. the importance of the company in relation to the whole STP. For instance, it might be the case that a firm has relatively few 
relationships but lies in a critical location within the network, being essential for the proper functioning of the STP.

\section{Closeness centrality}

The closeness centrality metric denotes how close a given node is to any other node in the network. Mathematically, it is represented as the inverse of the average distance between a node $v_{i} \in V$ and any other user $v_{j} \in V$, as follows:

$$
C C^{v_{i}}=\frac{|V|-1}{\sum v_{i} \neq v_{j}} \operatorname{sp(v_{i},v_{i})}
$$

where $\operatorname{sp}\left(v_{i}, v_{i}\right)$ is the number of connections on the shortest path between node $v_{i}$ and $v_{j}$.

Therefore, closeness centrality appears to be a promising metric to extract the importance of a firm in the STP as it reflects how far its potential connections extend. This might be interpreted, for instance, as the ability of a firm to connect to other companies (e.g. creating a strategic alliance, a trading partnership, etc.). Note that already connected nodes (neighbours) might be used as catalysts for the new connection by providing information concerning reputation, ways of working, requirement fulfilment, etc. on the one hand and providing references, allowing neighbours to act as referees, on the other.

\section{Betweenness centrality}

The betweenness centrality metric aims to measure the frequency with which a given node appears on the shortest path between any two nodes of the network. In other words, it is a measure based on how well a user is placed on the paths on which it lies (Freeman, 1977). Let $n p\left(v_{j}, v_{k}\right)$ be the number of paths between $v_{j} \in V$ and $v_{k} \in V$. Then, we obtain the centrality of node $v_{i}$ in terms of connecting $v_{j}$ and $v_{k}$ as the ratio:

$$
\frac{n p_{v_{i}}\left(v_{j}, v_{k}\right)}{n p\left(v_{j}, v_{k}\right)}
$$

Generalizing to obtain the betweenness centrality of node $v_{i}$, we obtain equation (4):

$$
B C^{v_{i}}=\sum_{v_{j} \neq v_{k} \neq v_{i}} \frac{\frac{n p_{v_{i}}\left(v_{j}, v_{k}\right)}{n p\left(v_{j}, v_{k}\right)}}{\frac{1}{2}(|V|-1)(|V|-2)}
$$


Similarly to closeness centrality, this metric is presented as a promising estimate for measuring the relevance of a firm and also for exploring the influence those firms may have in a potential mediation to start a new joint business relationship.

\section{Eigenvector centrality}

Eigenvector centrality, proposed by Bonacich in (Bonacich, 1987), is able to represent the importance of a node in the network. Let $\operatorname{EC}(G)$ be the eigenvector centrality associated with a network $\mathrm{G}$, the crux is that the centrality of a node is proportional to the sum of the centrality of its neighbours. Formally:

$$
\lambda \cdot E C^{v_{i}}(G)=\sum_{v_{j}} g_{i j} E C^{v_{j}}(G)
$$

in which $g_{i j}$ takes the value 1 if $\left(v_{i}, v_{j}\right) \in E$ and 0 otherwise (easily retrievable if $G$ is represented using an adjacency matrix) and $\lambda$ is a proportional factor (i.e. the eigenvalue).

\subsection{Structural analysis of the network}

As already mentioned, analysis of the centrality of the network seems to provide a key technique by which to observe the relationships in a STP. However, we argue that there are some other network metrics that can be used to gain a better understanding of the functioning of the STP from a management perspective. In this paper we explore two of these, namely the clustering coefficient and modularity.

\section{Clustering coefficient}

The clustering coefficient is based on the notion of transitive triples. Let $v_{i}, v_{j} \in V$ be two nodes in $G$ and $\left(v_{i}, v_{j}\right) \in E$ a link between them. Let $v_{k} \in V$ be another node in the same network and $\left(v_{i}, v_{k}\right) \in E$ an existing link in $G$. A transitive triple exists if $\left(v_{j}, v_{k}\right) \in E$. The clustering coefficient for a node then measures the fraction of transitive triples involving that node and its neighbours (connected nodes). This is calculated as shown in equation (6):

$$
C l^{v_{i}}=\frac{\#\left(v_{j}, v_{k}\right) \in E \mid v_{j} \neq v_{k}, v_{j} \in N_{v_{i}}, v_{k} \in N_{v_{i}}}{\frac{1}{2} \cdot d\left(v_{i}\right) \cdot\left(d\left(v_{i}\right)-1\right)}
$$

where $N_{v_{i}}$ stands for the set of neighbours of node $v_{i}$. 
Let us consider Fig., which depicts the calculation of clustering coefficients. In this case, $\mathrm{Cl}^{\mathrm{A}}=$ $2 / 3=0.66, \mathrm{Cl}^{\mathrm{B}}=1, \mathrm{Cl}^{\mathrm{C}}=0, \mathrm{Cl}^{\mathrm{D}}=2 / 6=0.33$ and $\mathrm{Cl}^{\mathrm{E}}=1$. The average clustering coefficient for this network is $\overline{C l^{G}}=0.598$.

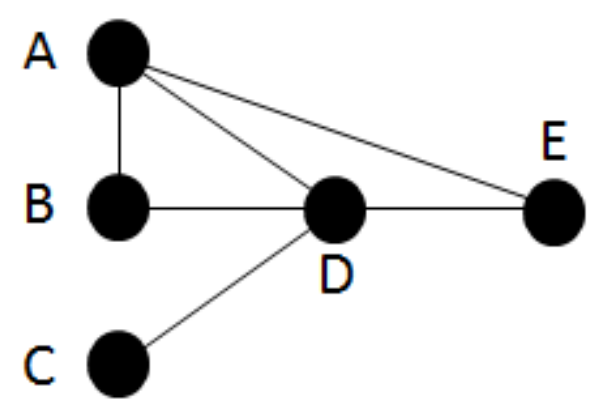

Fig. 2. Example of network

Therefore, clustering coefficient represents the cohesion a node has on its neighbours around. In the case of STPs it might denote the existing degree of linkage between firms as well as an estimate the emergence of new relations. Thus, if a new connection between firms $\mathrm{C}$ and $\mathrm{E}$ (in the example above) emerges, it might be reasonable to think that it is due to the influent presence of $\mathrm{D}$ instead of any other circumstances.

\section{Modularity}

The vertices in many networks fall naturally into groups or communities, sets of vertices within which there are many edges, with only a smaller number of edges between the vertices of different groups. Modularity is not a metric in itself but rather a technique that allows the identification of communities of nodes in a network. Formally, modularity gauges the proportion of edges that lie within communities minus the expected value of the same quantity in a graph, such that all nodes have the same degrees but links are generated uniformly at random. In other words, it is the fraction of the edges falling within the given groups minus the expected fraction if edges were distributed at random. This notion of community partition using modularity was first proposed by Newman and Girvan (Newman \& Girvan, 2004). The algorithm to compute this is based on an iterative process that chooses (in each iteration) a subset of nodes for which it calculates a modularity ratio. Mathematically, it is depicted as follows:

$$
M(\Pi, G)=\sum_{\pi \in \Pi} e_{\pi \pi}(G)-\sum_{\pi \in \Pi, \pi^{\prime} \in \Pi, \pi \prime \prime \in \Pi} e_{\pi \pi^{\prime}}(G) e_{\pi^{\prime} \pi^{\prime \prime}}(G)
$$


where $\Pi$ stands for any community structure and $e_{\pi \pi}{ }^{\prime}(G)$ represents the fraction of all edges in the network that connect nodes in $\pi$ to nodes in $\pi^{\prime}$.

Modularity presents itself as a powerful way of dividing the networks generated in an STP into different groups, which in turn reflect the internal structure of the STP whatever parameters it is based on. That is, modularity attempts to split the network into different communities but does not say anything about the reasons why this occurs. However, some conclusions may be derived, for instance, by comparing the communities generated to the different firms grouped by sector type, number of employees, or other factors.

\section{CASE STUDY: THE WALQA STP}

In Spain, STPs are currently experiencing a period of strong development. At the end of 2013, a total of 6,286 companies and institutions were established in the STPs of the APTE, with an employment volume of 147,740 workers. Of these, 30,978 were recorded as carrying out research and development $(R \& D)$, representing approximately $13 \%$ of those engaged in $R \& D$ in the whole of Spain. With respect to turnover, the STPs of the APTE billed a total of $€ 21.12$ billion in 2013, representing approximately $2 \%$ of gross domestic product (GDP). In 2013, these STPs invested $€ 1.43$ billion in R\&D, constituting approximately $9 \%$ of total R\&D investment in Spain.

More specifically, the case that concerns us here, the Walqa STP, emerged with the objective of becoming a magnet for innovation and $\mathrm{R} \& \mathrm{D}$, especially in the fields of information technologies, biotechnology and renewable energies. Since 2002, it has been a full member of the APTE and of the IASP. The Walqa STP has a total surface area of 53 hectares and four of its six phases have already been developed. It currently has 14 buildings in which local, regional, national and multinational firms, new entrepreneurs, universities and technology centres have been established. In December 2013, the Walqa STP already had 900 workers in the more than 60 companies with a presence there.

To analyse the network companies established in the Walqa STP, a survey was developed (LatorreMartínez, Navarro-Elola, Pastor-Tejedor, \& Íñiguez-Berrozpe, 2013), which was sent to all the organizations (first phase in Fig. 1). The survey contained several types of questions. First, the survey included questions regarding the characteristics of the entities, such as the number of workers employed, number of years in the park, turnover of the companies, etc. Second, they were also asked about their levels of satisfaction, for example with other entities and aspects for the companies arising from their 
position in the Walqa STP. For these, respondents were asked to rate their level of satisfaction by indicating the extent of their agreement/disagreement with a series of statements on a seven-point Likert scale (anchored at 1 "strongly disagree" and 7 "strongly agree"). Finally, respondents were asked about which other entities they had relationships with (regardless of the type of relationship: technological/commercial cooperation or body shopping). These surveys were carried out in two different ways: by personal interviews or as online surveys. A response rate of $96.4 \%$ was achieved with a total of 53 entities of the 56 targeted by the study. A summary of the characteristics of the Walqa STP is shown in Table 1.

Table 1

Characteristics of the sample

\begin{tabular}{llr}
\hline Variable & Descriptor & $\%$ \\
\hline Position of the respondent: & & 32 \\
& Owner & 19 \\
& Managing Director & 8 \\
& R\&D Director & 41 \\
& Other & \\
\hline
\end{tabular}

Origin of the enterprise:

Independent external enterprise $\quad 50$

Subsidiary of another larger external corporation $\quad 28$

$\begin{array}{ll}\text { Start-up } & 10\end{array}$

$\begin{array}{lr}\text { Other } & 12\end{array}$

\section{Currently, the company is:}

Independent 59

A subsidiary with considerable autonomy 23

A subsidiary with little autonomy $\quad 12$

Other 6

Sector:

$\begin{array}{ll}\text { ICT } & 35.8\end{array}$

dot-com 11.3

Universities, R\&D Centres $\quad 11.3$

Medicine and Biotechnology $\quad 7.5$ 


\begin{tabular}{|c|c|c|}
\hline Variable & Descriptor & $\%$ \\
\hline & Engineering & 7.5 \\
\hline & Consulting & 5.6 \\
\hline & Energy-Environment & 5.6 \\
\hline \multicolumn{3}{|c|}{ Asset value in 2011: } \\
\hline & $>€ 1,000,000$ & 34 \\
\hline & $€ 500,001-1,000,000$ & 15 \\
\hline & $€ 300,001-500,000$ & 8 \\
\hline & $€ 100,001-300,000$ & 6 \\
\hline & $<€ 100,000$ & 37 \\
\hline \multicolumn{3}{|c|}{ Turnover in 2011: } \\
\hline & $>€ 5,000,000$ & 12 \\
\hline & $€ 1,000,001-5,000,000$ & 16 \\
\hline & $€ 300,001-100,000$ & 18 \\
\hline & $€ 100,001-300,000$ & 20 \\
\hline & $<€ 100,000$ & 34 \\
\hline \multicolumn{3}{|c|}{ Years in the park: } \\
\hline & $>10$ years & 14 \\
\hline & $5-10$ years & 28 \\
\hline & $1-5$ years & 48 \\
\hline & $<1$ year & 10 \\
\hline
\end{tabular}

\subsection{From data collection to network generation}

Having presented the STP chosen to apply our approach, we turn to how we generated the network from the data collected in the surveys (phase 2 in Fig. 1). Taking our network model (introduced in Section 3.1), let $G=(V, E)$ be the graph representing the network for the Walqa STP, in which $V$ is the set of firms operating in the STP and $E$ stands for the set of existing (or past) entrepreneurial relations between the firms in $V$. In other words, if two certain firms are linked in the network, they necessarily have (or had) a type of business relationship. Note that, in this case, we assume these relations are bidirectional, which entails that graph $G$ will be undirected. Nevertheless, business relationships among the same participants might occur at different points in time, thus generating different links between them 
in the network (note respondents of the survey were asked about which other entities they had relationships with, regardless the type of relationship: technological/commercial, cooperation or body shopping).

As can be seen from Table 1, the main sector in which the enterprises are active is ICT (18\%), followed by Computing, Software and Hardware (9\%), Energy-Environment (7\%), Medicine and Biotechnology (4\%) and finally Electronics (2\%) and R\&D Centres (1\%). With respect to the value of assets in $2011,34 \%$ of firms in the sample have assets valued at over $€ 1$ million and $14 \%$ have assets of $€ 500,001$ to $€ 1,000,000$. What is noteworthy is the fact that $37 \%$ of the sample firms have assets valued at less than $€ 100,000$. As far as turnover is concerned, it is significant that $34 \%$ billed less than $€ 100,000$ in 2011 , followed by $20 \%$ which billed between $€ 100,000$ and $€ 300,000$. Furthermore, $61 \%$ employ fewer than 10 workers. Finally, two quite different groups can be found according to the number of years that the companies have been established in the park: almost half of them (48\%) have been in the park for 1-5 years, whereas $28 \%$ have been there for $5-10$ years.

\subsection{Results}

To validate the approach proposed in the previous sections, we use the network generated as explained above (see Section 4.1 for more detail). Table 2 summarizes the results obtained for the set of metrics of proposed centrality, which give rise to some interesting outcomes. By analysing degree centrality, we conclude that there are two main nodes forming part of numerous relationships. Note that both of these entities are universities. In this case, it is clear that educational nodes and their interest in innovation and technology transfer foster cooperation between nodes in the STP.

\section{Table 2}

Results obtained for the Walqa STP

\begin{tabular}{lccccccc}
\hline \multicolumn{1}{c}{ Id } & Sector & $\begin{array}{c}\text { Degree } \\
\text { centrality }\end{array}$ & $\begin{array}{c}\text { Closeness } \\
\text { Centrality }\end{array}$ & $\begin{array}{c}\text { Betweenness } \\
\text { Centrality }\end{array}$ & $\begin{array}{c}\text { Clustering } \\
\text { Coefficient }\end{array}$ & $\begin{array}{c}\text { Eigenvector } \\
\text { Centrality }\end{array}$ & $\begin{array}{c}\text { Modularity } \\
\text { Class }\end{array}$ \\
\hline Accenture & $\mathrm{C}$ & 0,02 & 4,02 & 0,00 & 0,00 & 0,00 & 8 \\
Adhesivos de Vinilo & $\mathrm{W}$ & 0,00 & 0,00 & 0,00 & 0,00 & 0,00 & 0 \\
Aid4net & $\mathrm{T}$ & 0,04 & 2,87 & 44,00 & 0,00 & 0,09 & 9 \\
APM & $\mathrm{T}$ & 0,02 & 3,07 & 0,00 & 0,00 & 0,00 & 7 \\
AST & $\mathrm{O}$ & 0,06 & 2,82 & 4,00 & 0,00 & 0,13 & 8 \\
Balmar & $\mathrm{I}$ & 0,00 & 0,00 & 0,00 & 0,00 & 0,00 & 1 \\
\hline
\end{tabular}




\begin{tabular}{|c|c|c|c|c|c|c|c|}
\hline Id & Sector & $\begin{array}{l}\text { Degree } \\
\text { centrality }\end{array}$ & $\begin{array}{l}\text { Closeness } \\
\text { Centrality }\end{array}$ & $\begin{array}{l}\text { Betweenness } \\
\text { Centrality }\end{array}$ & $\begin{array}{l}\text { Clustering } \\
\text { Coefficient }\end{array}$ & $\begin{array}{l}\text { Eigenvector } \\
\text { Centrality }\end{array}$ & $\begin{array}{l}\text { Modularity } \\
\text { Class }\end{array}$ \\
\hline Barrabes & $\mathrm{W}$ & 0,06 & 2,98 & 0,25 & 0,50 & 0,16 & 10 \\
\hline Cadwork & I & 0,00 & 0,00 & 0,00 & 0,00 & 0,00 & 2 \\
\hline Cetresce DIFERENTIA & $\mathrm{T}$ & 0,04 & 3,24 & 0,00 & 0,00 & 0,03 & 12 \\
\hline China Chana & $\mathrm{O}$ & 0,04 & 2,73 & 0,00 & 0,00 & 0,15 & 6 \\
\hline Consultoria San Martin & $\mathrm{C}$ & 0,06 & 3,07 & 0,67 & 0,00 & 0,03 & 12 \\
\hline Corp. Arag. Radio y Tv. & $\mathrm{O}$ & 0,06 & 2,33 & 0,71 & 0,00 & 0,15 & 7 \\
\hline Cruz Roja & $\mathrm{O}$ & 0,00 & 0,00 & 0,00 & 0,00 & 0,00 & 3 \\
\hline D\&T Global & $\mathrm{T}$ & 0,09 & 2,24 & 15,86 & 0,25 & 0,04 & 12 \\
\hline Deloitte & $\mathrm{T}$ & 0,04 & 2,73 & 0,00 & 0,00 & 0,15 & 6 \\
\hline Ecomputer & $\mathrm{T}$ & 0,15 & 2,73 & 10,06 & 0,13 & 0,24 & 10 \\
\hline Electrobin & $\mathrm{E}$ & 0,13 & 2,18 & 0,71 & 0,83 & 0,48 & 7 \\
\hline Exito & $\mathrm{O}$ & 0,09 & 2,24 & 18,71 & 0,15 & 0,00 & 9 \\
\hline FADOT & $\mathrm{V}$ & 0,08 & 2,62 & 0,00 & 1,00 & 0,29 & 6 \\
\hline Frogtek & $\mathrm{T}$ & 0,17 & 2,38 & 11,88 & 0,20 & 0,37 & 10 \\
\hline Fundacion Hidrogeno & $\mathrm{V}$ & 0,08 & 2,29 & 0,71 & 0,67 & 0,40 & 6 \\
\hline Funidelia & $\mathrm{W}$ & 0,00 & 0,00 & 0,00 & 0,00 & 0,00 & 4 \\
\hline HD MEDI & B & 0,00 & 0,00 & 0,00 & 0,00 & 0,00 & 5 \\
\hline $\mathrm{Hdos} \mathrm{O}$ & B & 0,13 & 2,27 & 5,95 & 0,33 & 0,35 & 7 \\
\hline I.T.A. & $\mathrm{v}$ & 0,40 & 1,96 & 49,41 & 0,28 & 0,94 & 6 \\
\hline Ia Soft & $\mathrm{T}$ & 0,15 & 2,18 & 3,12 & 0,65 & 0,61 & 7 \\
\hline Igeo 2 & I & 0,06 & 2,31 & 0,71 & 0,67 & 0,21 & 7 \\
\hline Indra & $\mathrm{T}$ & 0,11 & 2,78 & 30,13 & 0,08 & 0,20 & 6 \\
\hline Inycom & $\mathrm{E}$ & 0,26 & 2,02 & 46,15 & 0,38 & 0,68 & 6 \\
\hline Itisnet & $\mathrm{O}$ & 0,04 & 2,91 & 0,00 & 0,00 & 0,09 & 9 \\
\hline Limite 0 & $\mathrm{~T}$ & 0,06 & 2,62 & 1,04 & 0,00 & 0,15 & 9 \\
\hline Macraut & I & 0,04 & 2,64 & 0,00 & 0,00 & 0,15 & 7 \\
\hline Marketing Adjal & $\mathrm{O}$ & 0,02 & 3,84 & 0,00 & 0,00 & 0,02 & 9 \\
\hline Micromat & $\mathrm{T}$ & 0,13 & 2,24 & 108,95 & 0,00 & 0,23 & 8 \\
\hline Movilitas & $\mathrm{T}$ & 0,32 & 1,93 & 153,60 & 0,25 & 0,60 & 9 \\
\hline Observatorio Aragones & $\mathrm{V}$ & 0,25 & 2,20 & 43,99 & 0,16 & 0,54 & 10 \\
\hline Ox- CTA & B & 0,06 & 2,36 & 0,40 & 0,67 & 0,36 & 6 \\
\hline Podoactiva & B & 0,13 & 2,27 & 22,61 & 0,25 & 0,29 & 10 \\
\hline Servicios Normativos & E & 0,09 & 2,56 & 14,48 & 0,33 & 0,20 & 12 \\
\hline Seycob & $\mathrm{T}$ & 0,00 & 0,00 & 0,00 & 0,00 & 0,00 & 11 \\
\hline
\end{tabular}




\begin{tabular}{lccccccc}
\hline \multicolumn{1}{c}{ Id } & Sector & $\begin{array}{c}\text { Degree } \\
\text { centrality }\end{array}$ & $\begin{array}{c}\text { Closeness } \\
\text { Centrality }\end{array}$ & $\begin{array}{c}\text { Betweenness } \\
\text { Centrality }\end{array}$ & $\begin{array}{c}\text { Clustering } \\
\text { Coefficient }\end{array}$ & $\begin{array}{c}\text { Eigenvector } \\
\text { Centrality }\end{array}$ & $\begin{array}{c}\text { Modularity } \\
\text { Class }\end{array}$ \\
\hline Soltic & $\mathrm{T}$ & 0,23 & 1,91 & 144,11 & 0,08 & 0,41 & 12 \\
System One & $\mathrm{T}$ & 0,06 & 3,04 & 45,40 & 0,00 & 0,00 & 8 \\
T.G.S.S. & $\mathrm{O}$ & 0,04 & 3,09 & 1,40 & 0,00 & 0,07 & 8 \\
Tafyesa & $\mathrm{T}$ & 0,25 & 2,09 & 72,91 & 0,36 & 0,60 & 7 \\
Tap Consultoria & $\mathrm{C}$ & 0,19 & 2,29 & 31,42 & 0,23 & 0,34 & 12 \\
Telefonica & $\mathrm{T}$ & 0,19 & 2,16 & 28,15 & 0,47 & 0,62 & 6 \\
Tunca Time & $\mathrm{W}$ & 0,09 & 2,47 & 1,62 & 0,33 & 0,33 & 6 \\
Universidad San Jorge & $\mathrm{V}$ & 0,62 & 1,67 & 316,64 & 0,09 & 0,94 & 7 \\
Universidad Zaragoza & $\mathrm{V}$ & 0,70 & 1,76 & 261,97 & 0,08 & 1,00 & 6 \\
Veintiocho & $\mathrm{W}$ & 0,17 & 2,27 & 91,26 & 0,07 & 0,17 & 12 \\
Visitaragon & $\mathrm{W}$ & 0,02 & 2,89 & 0,00 & 0,00 & 0,06 & 12 \\
Web Dreams & $\mathrm{T}$ & 0,11 & 2,27 & 6,79 & 0,00 & 0,35 & 10 \\
Websca & $\mathrm{T}$ & 0,04 & 3,18 & 1,22 & 0,00 & 0,06 & 12 \\
\hline
\end{tabular}

Fig. 2 illustrates a graphical representation of the network generated, emphasizing the degree centrality of nodes (the greater the size of nodes, the higher the degree centrality). Nodes are coloured according to productive sector. Focusing attention on the closeness and betweenness centralities, we can observe that again the two universities show the lowest outcomes for closeness (having a short average distance compared to any other node in the network) and the highest betweenness (are more likely to be present in the path between any two nodes). With this in mind, these nodes should be considered good proxies for connecting other firms for potential new joint ventures. Eigenvector centrality, as already explained, represents the core importance of a node in the network. In our study, nodes with more importance meet other metrics, highlighting those firms (in this case, universities) which are cornerstones in the STP. From a management point of view, one might conclude that the coexistence of both nodes is essential if we want the STP to be connected. 


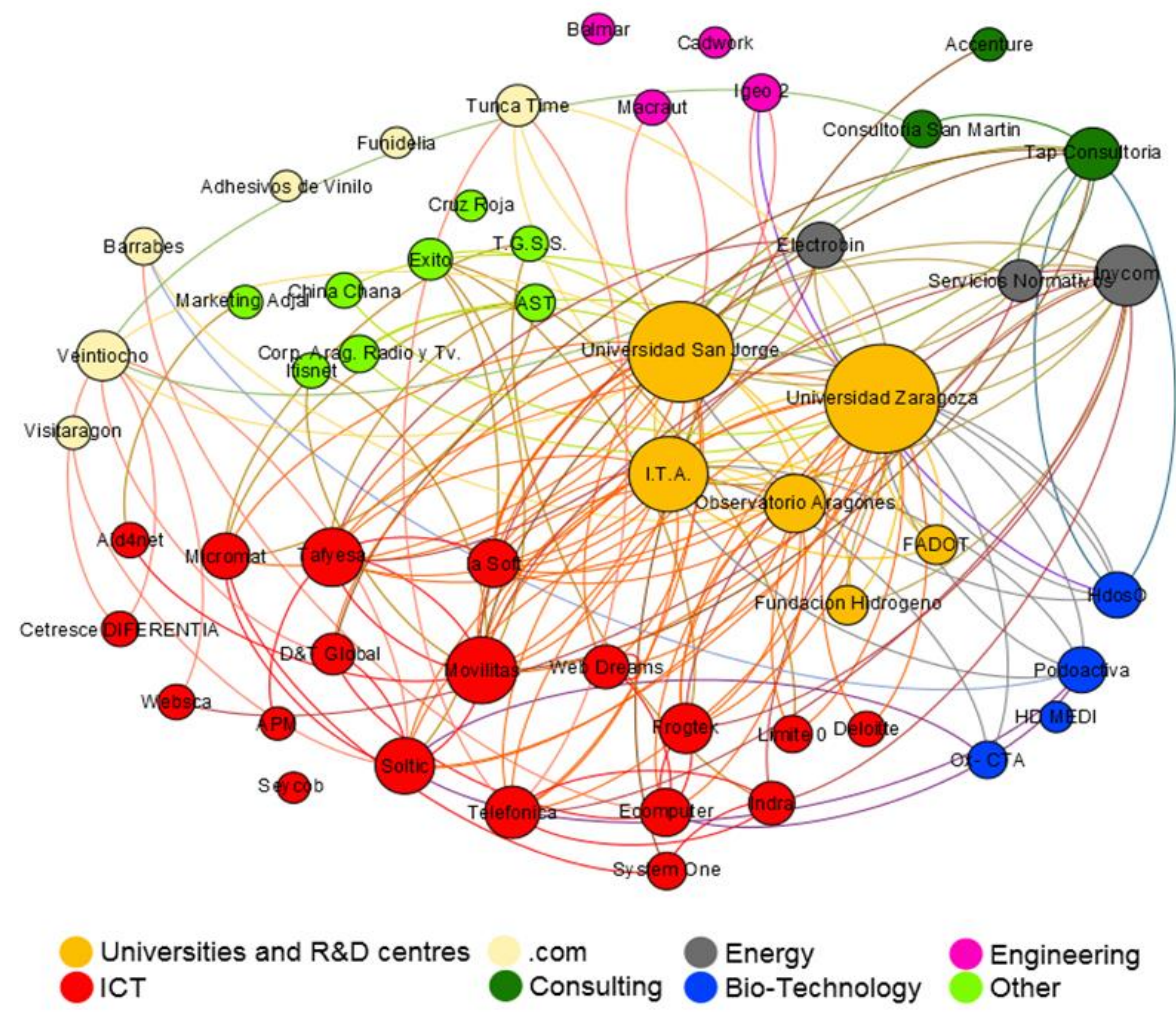

Fig. 3. Network generated from the Walqa STP displayed by sector type

If we examine the metrics proposed in our approach for measuring the structure of the network, we obtain the following results (also in Fig. 3). First, considering the clustering coefficient of nodes, we see that important nodes have many connections that result in poor values. The more connections a node has the lower the likelihood that it will form a tight community. However, if we focus on modularity to extract communities of nodes from the network structure, we observe that there are four clear divisions. We show the different communities in Fig. 3. Here, the same colours represent the same communities. Thus, we see interesting properties in that firms from different sectors form part of the same community, demonstrating that heterogeneous relationships are more important than one might think a priori. These results could, for instance, lead to change in the strategy of expansion for the STP by trying to attract other companies that could fit in one of these four communities. However, the same strategy could be used to expel those firms that appear isolated in the network. 


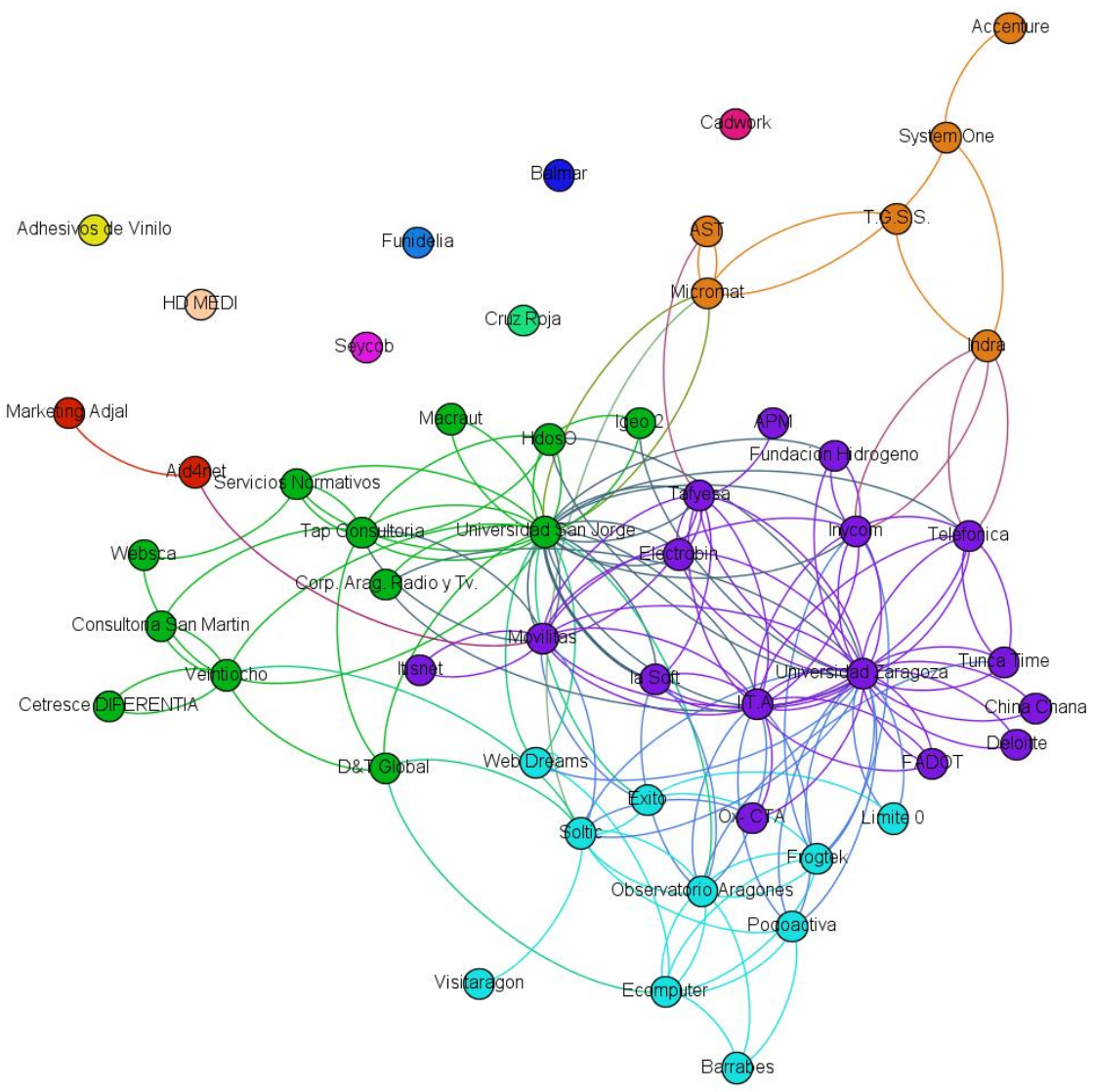

Fig. 4. Communities identified using modularity

\section{DISCUSSION}

We set out to investigate STPs from the perspective of inter-organizational relationships. As a result, we propose a generic framework to study the performance of inter-organizational relationships in STPs. Reviewing other studies that analyze inter-organizational relationships that exist within STPs can be useful in this process. To this aim, we have considered various works in which the authors have confirmed their results empirically in relation to parks located in different parts of the word. These analyses provide a concrete idea of whether these relationships actually exist and if so, among which entities and how they are constituted. 
The attraction between different companies, whether of the same or different kinds, is based on the objectives and management established by the STPs themselves (Bigliardi, Dormio, Nosella, \& Petroni, 2006; Castells \& Hall, 1994; Cheng et al., 2013; Ratinho \& Henriques, 2010). Companies make the decision to settle in an STP encouraged by various factors that can improve their work. Regional public policies (Guy, 1996) try to encourage this decision through the careful provision of infrastructure, cheaper land prices or advantageous financing (Radosevic \& Myrzakhmet, 2009) and this involves an interesting reduction in business costs (A. Link \& Scott, 2003). However, companies also look for other effects associated with the concurrence of technology-based companies (Hansson, Husted, \& Vestergaard, 2005), such as the knowledge generated and shared, the status or prestige (Felsenstein, 1994) of being located in an important environment of innovation and technological progress, and the management facilities (Dettwiler, Lindelöf, \& Löfsten, 2006), all of which in many cases emerge from learning achieved in the process of incubation (Avnimelech, Schwartz, \& Bar-El, 2007; Colombo \& Delmastro, 2002), as well as - clearly - the links between organizations, born in the field of the activity itself. All of these, in short, are factors that improve the work of the company, reduce its costs and increase its research productivity (Siegel, Westhead, \& Wright, 2003). Nevertheless, concentrating the focus on inter-organizational relationships, past experiences show that these do not occur in all cases: in some STPs, these relationships are virtually non-existent within the STP, albeit they exist with other alien entities outside the STP (Radosevic \& Myrzakhmet, 2009; Vandierdonck, Debackere, \& Rappa, 1991).

It is important to emphasize that in STPs where links between different types of existing organizations have been identified, these links have not been very numerous and have been directed very often primarily towards a single master node; that is, a network of reduced density and diversity of interactions is described. So, in the relationships observed within STPs, in most cases, a connection between companies and a university is established, specifically university research groups, which are attributed a role of centrality in the network of relationships (Löfsten \& Lindelöf, 2002). Therefore, this is considered interaction between the public and the private sectors.

This relationship between companies and a university is usually built in the field of research and it is of a formal nature. The company contacts the university looking for increasing its knowledge or to bring the fruits of university research into the business environment, in other words, seeking to turn basic research into applied research (A. Link \& Scott, 2003). One of its features is, therefore, that both benefit from this communication, the university providing theoretical and basic knowledge (Löfsten \& Lindelöf, 2002) and the company providing a return through the possibility that the theory will be applied (A. Link 
\& Scott, 2003). However, some evidence has indicated that SPs are not so effective in establishing knowledge linkages with local research institutes (Chan, Oerlemans, \& Pretorius, 2010; Garnsey \& Heffernan, 2005).

A relationship between companies and a university can be considered formal when it is constituted through collaborative agreements or contracts that contain the conditions governing the relationship (Fukugawa, 2006). However, it has been observed that, in general, links are more casual, relating rather to the field of personal relationships of the employees (Phillimore, 1999), both in the few relationships established between companies and in relationships between companies and universities (Bakouros et al., 2002; Massey et al., 2003; Vedovello, 1997). Other studies have found that these informal links also occur between companies inside and outside the park (Chan et al., 2010).

The success of inter-organizational relationships rests on having in-depth knowledge of their characteristics. However, the works reviewed in the literature above do not confront this issue from a sufficiently generic and holistic perspective. With this in mind, we proposed a novel approach, presenting the ISA framework, which is based on the assessment of the STP from a network analysis point of view. We consider this framework could be used as an evaluation tool for measuring the performance of a STP at three different levels: i) individual entities (research centres, universities, innovation companies, etc.); ii) STP global management; iii) productive sector development.

\section{CONCLUSIONS}

In this study we have presented a quantitative tool to assess the relationships emerging in STPs. We propose a framework, the ISA framework, which provides a multi-level criteria tool to analyse the relationships between entities in a STP. This framework allows the STP to be modelled as a network, thus providing different methods to investigate different relationship levels between entities. The output of the ISA framework can provide important estimates for management in relation to the three perspectives presented: management of the individual entities, STP global management and productive sector management (e.g. clustering differentiation). We have applied the ISA framework to a real-world scenario, the Walqa STP, obtaining some interesting results.

In future work, we intend to study combinations of macroeconomic data from nodes and their links, in particular their type (commercial, technological, human resource movement, established networks). 
Another future research avenue is to explore the evolution of both the composition of the network and the relationships in the parks analysed, paying special attention to the sectoral evolution, as well as the growth in the relationships between R\&D centres and firms.

\section{REFERENCES}

Audretsch, B. (1998). Agglomeration and the location of innovative activity. Oxford Review of Economic Policy, 14(2), 18-29. http://doi.org/10.1093/oxrep/14.2.18

Audretsch, D. B., Bozeman, B., Combs, K. L., Feldman, M., Link, A. N., Siegel, D. S., ... Wessner, C. (2002). The Economics of Science and Technology. The Journal of Technology Transfer, 27(2), 155-203. http://doi.org/10.1023/A:1014382532639

Autio, E., Sapienza, H. J., \& Almeida, J. G. (2000). Effects of Age at Entry, Knowledge Intensity, and Imitability on International Growth. The Academy of Management Journal, (5), 909.

Avnimelech, G., Schwartz, D., \& Bar-El, R. (2007). Entrepreneurial High-tech Cluster Development: Israel's Experience with Venture Capital and Technological Incubators. European Planning Studies, 15(9), 1181-1198. http://doi.org/10.1080/09654310701529078

Aydalot, P. (1986). Milieux innovateurs en Europe.

Bakouros, Y. L., Mardas, D. C., \& Varsakelis, N. C. (2002). Science park, a high tech fantasy?: an analysis of the science parks of Greece. Technovation, 22(2), 123-128. http://doi.org/10.1016/S0166-4972(00)00087-0

Basile, A. (2011). Networking System and Innovation Outputs: The Role of Science and Technology Parks. International Journal of Business and Management, 6(5), 3. http://doi.org/10.5539/ijbm.v6n5p3

Bigliardi, B., Dormio, A. I., Nosella, A., \& Petroni, G. (2006). Assessing science parks' performances: directions from selected Italian case studies. Technovation, 26(4), 489-505. http://doi.org/10.1016/j.technovation.2005.01.002

Bonacich, P. (1987). Power and Centrality: A Family of Measures. American Journal of Sociology, 92(5), 1170-1182. Retrieved from http://www.jstor.org/stable/2780000

Bosma, N., van Praag, M., Thurik, R., \& de Wit, G. (2004). The Value of Human and Social Capital Investments for the Business Performance of Startups. Small Business Economics, 23(3), 227-236. http://doi.org/10.1023/B:SBEJ.0000032032.21192.72

Castells, P., \& Hall, P. (1994). Technopoles of the world: The making of the 21st century industrial Complexes Routledge. New York.

Cebrián Tarrasón, D., Vidal, R., Salmerón, J. L., Bertolín, J. A., \& Negre, P. (2011). Análisis de las empresas de base tecnológica de un parque científico y tecnológico basado en técnicas de redes sociales. Asociación Española de Dirección e Ingeniería de Proyectos (AEIPRO).

Chan, K.-Y. A., Oerlemans, L. A. G., \& Pretorius, M. W. (2010). Knowledge exchange behaviours of science park firms: the innovation hub case. Technology Analysis \& Strategic Management, 22(2), 207-228. http://doi.org/10.1080/09537320903498546 
Cheng, F., van Oort, F., Geertman, S., \& Hooimeijer, P. (2013). Science Parks and the Co-location of High-tech Small- and Medium-sized Firms in China's Shenzhen. Urban Studies, 51(5), 1073-1089. http://doi.org/10.1177/0042098013493020

Colombo, M. G., \& Delmastro, M. (2002). How effective are technology incubators? Research Policy, 31(7), 1103-1122. http://doi.org/10.1016/S0048-7333(01)00178-0

Dettwiler, P., Lindelöf, P., \& Löfsten, H. (2006). Business environment and property management issues: a study of growth firms in Sweden. Journal of Corporate Real Estate, 8(3), 120-133.

Dyer, J. H., \& Singh, H. (1998). The Relational View: Cooperative Strategy and Sources of Interorganizational Competitive Advantage. The Academy of Management Review, (4), 660.

Felsenstein, D. (1994). University-related science parks - "seedbeds" or "enclaves" of innovation? Technovation, 14(2), 93-110. http://doi.org/10.1016/0166-4972(94)90099-X

Freeman, L. C. (1977). A Set of Measures of Centrality Based on Betweenness. Sociometry, 40(1), 35-41.

Fukugawa, N. (2006). Science parks in Japan and their value-added contributions to new technologybased firms. International Journal of Industrial Organization, 24, 381-400. http://doi.org/10.1016/j.ijindorg.2005.07.005

Garnsey, E., \& Heffernan, P. (2005). High-technology clustering through spin-out and attraction: The Cambridge case. Regional Studies, 39(8), 1127-1144. http://doi.org/10.1080/00343400500328289

Gower, S. M., \& Harris, F. C. (1994). Science Parks in the UK. Property Management, 12(4), 24-33. http://doi.org/10.1108/02637479410071036

Gronum, S., Verreynne, M.-L., \& Kastelle, T. (2012). The Role of Networks in Small and Medium-Sized Enterprise Innovation and Firm Performance. Journal of Small Business Management, 50(2), 257282. http://doi.org/10.1111/j.1540-627X.2012.00353.x

Guy, I. (1996). A look at Aston Science Park. TECHNOVATION, 16(5), 217-218.

Hansson, F., Husted, K., \& Vestergaard, J. (2005). Second generation science parks: from structural holes jockeys to social capital catalysts of the knowledge society. Technovation, 25(9), 1039-1049. http://doi.org/10.1016/j.technovation.2004.03.003

Hodgson, B. (1996). A methodological framework to analyse the impact of science and technology parks. The Economics of Science Parks. IASP and AURRP.

Jackson, M. O. (2008). Social and Economic Networks. Princeton, NJ, USA: Princeton University Press.

Kirby, D. A., \& Cox, J. (2006). Guest editorial: New technology based firms in the knowledge economy. International Entrepreneurship and Management Journal, 2(2), 139-144. http://doi.org/10.1007/s11365-006-8680-4

Koka, B. R., \& Prescott, J. E. (2002). Strategic Alliances as Social Capital: A Multidimensional View. Strategic Management Journal, (9), 795.

Latorre-Martínez, M., Navarro-Elola, L., Pastor-Tejedor, J., \& Íñiguez-Berrozpe, T. (2013). Analysis of the Network of Relations of Organizations Set up at Walqa Technology Park. Advances in Sustainable \& Competitive Manufacturing Systems, 1335.

Lesser, E., \& Prusak, L. (1999). Communities of practice, social capital and organizational knowledge. Information Systems Review, 1(1), 3-10. 
Link, A. N., \& Scott, J. T. (2007). The economics of university research parks. Oxford Review of Economic Policy, 23(4), 661-674. http://doi.org/10.1093/oxrep/grm030

Link, A. N., \& Siegel, D. S. (2007). Innovation, entrepreneurship, and technological change.

Link, A., \& Scott, J. (2003). US science parks: the diffusion of an innovation and its effects on the academic missions of universities. INTERNATIONAL JOURNAL OF INDUSTRIAL ORGANIZATION, 21(9), 1323-1356.

Löfsten, H., \& Lindelöf, P. (2002). Science Parks and the growth of new technology-based firmsacademic-industry links, innovation and markets. Research Policy, 31(6), 859-876. http://doi.org/10.1016/S0048-7333(01)00153-6

Löfsten, H., \& Lindelöf, P. (2005). R\&D networks and product innovation patterns-academic and nonacademic new technology-based firms on Science Parks. Technovation, 25(9), 1025-1037. http://doi.org/10.1016/j.technovation.2004.02.007

Maillat, D. (1995). Territorial dynamic, innovative milieus and regional policy. Entrepreneurship \& Regional Development, 7(2), 157-165.

Massey, D., Quintas, P., \& Wield, D. (2003). High-tech fantasies: Science parks in society, science and space. Routledge.

Nahapiet, J., \& Ghoshal, S. (1998). Social Capital, Intellectual Capital, and the Organizational Advantage. The Academy of Management Review, (2), 242.

Newman, M. E. J., \& Girvan, M. (2004). Finding and evaluating community structure in networks. Physical Review E, 69(2), 26113. http://doi.org/10.1103/PhysRevE.69.026113

Phillimore, J. (1999). Beyond the linear view of innovation in science park evaluation An analysis of Western Australian Technology Park. Technovation, 19(11), 673-680.

Ponds, R., Oort, F. v., \& Frenken, K. (2009). Innovation, spillovers and university-industry collaboration: an extended knowledge production function approach. Journal of Economic Geography, 10(2), 231-255. http://doi.org/10.1093/jeg/lbp036

Porter, M. E. (1985). The Competitive Advantage: Creating and Sustaining Superior Performance. NY: Free Press.

Radosevic, S., \& Myrzakhmet, M. (2009). Between vision and reality: Promoting innovation through technoparks in an emerging economy. Technovation, 29, 645-656. http://doi.org/10.1016/j.technovation.2009.04.001

Ratinho, T., \& Henriques, E. (2010). The role of science parks and business incubators in converging countries: Evidence from Portugal. Technovation, 30, 278-290. http://doi.org/10.1016/j.technovation.2009.09.002

Siegel, D. S., Westhead, P., \& Wright, M. (2003). Assessing the impact of university science parks on research productivity: exploratory firm-level evidence from the United Kingdom. International Journal of Industrial Organization, 21, 1357-1369. http://doi.org/10.1016/S0167-7187(03)00086-9

Tsai, W. (2000). The formation of intraorganizational linkages. Strategic Management Journal, 21(9), 925-939.

Vandierdonck, R., Debackere, K., \& Rappa, M. (1991). An Assessment of Science Parks - Towards a 
Better Understanding of Their Role in the Diffusion of Technological Knowledge. $R \& D$ MANAGEMENT, 21(2), 109-123.

Varga, A., Pontikakis, D., \& Chorafakis, G. (2012). Metropolitan Edison and cosmopolitan Pasteur? Agglomeration and interregional research network effects on European R\&D productivity. Journal of Economic Geography, 14(2), 229-263. http://doi.org/10.1093/jeg/lbs041

Vedovello, C. (1997). Science parks and university-industry interaction: Geographical proximity between the agents as a driving force. Technovation, 17(9), 491-531. http://doi.org/10.1016/S01664972(97)00027-8

Weber, A., \& Pick, G. (1909). Über den standort der industrien. JCB Mohr.

Westhead, P., \& Storey, D. J. (1995). Links between higher education institutions and high technology firms. Omega, 23(4), 345-360. http://doi.org/10.1016/0305-0483(95)00021-F 


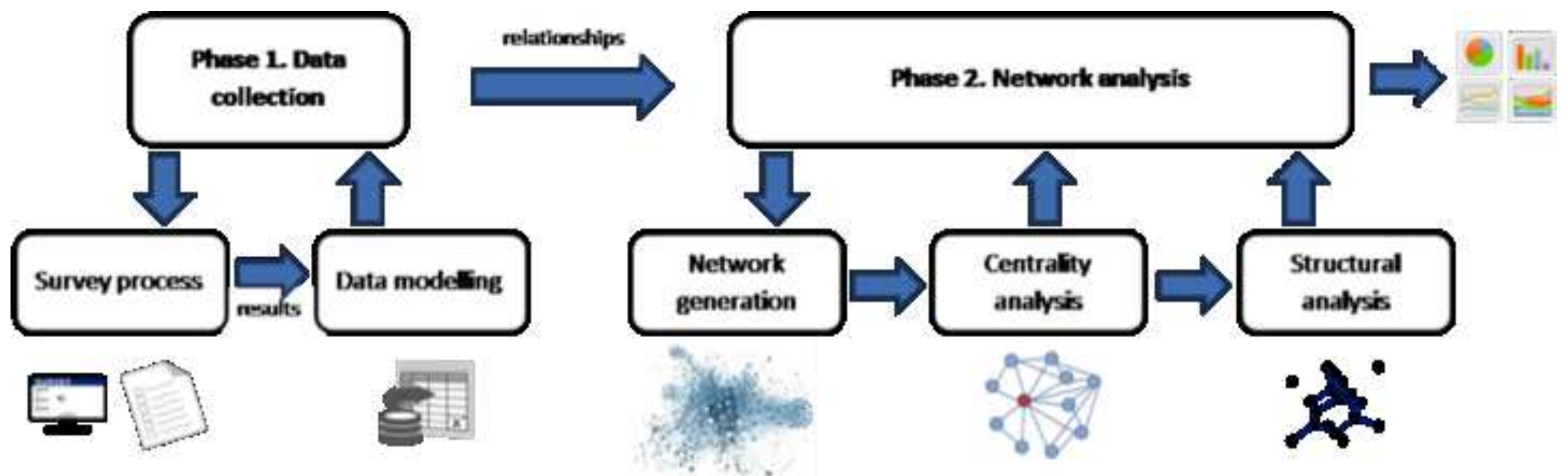


Click here to download Figure Figure 2.jpg $\stackrel{ \pm}{*}$

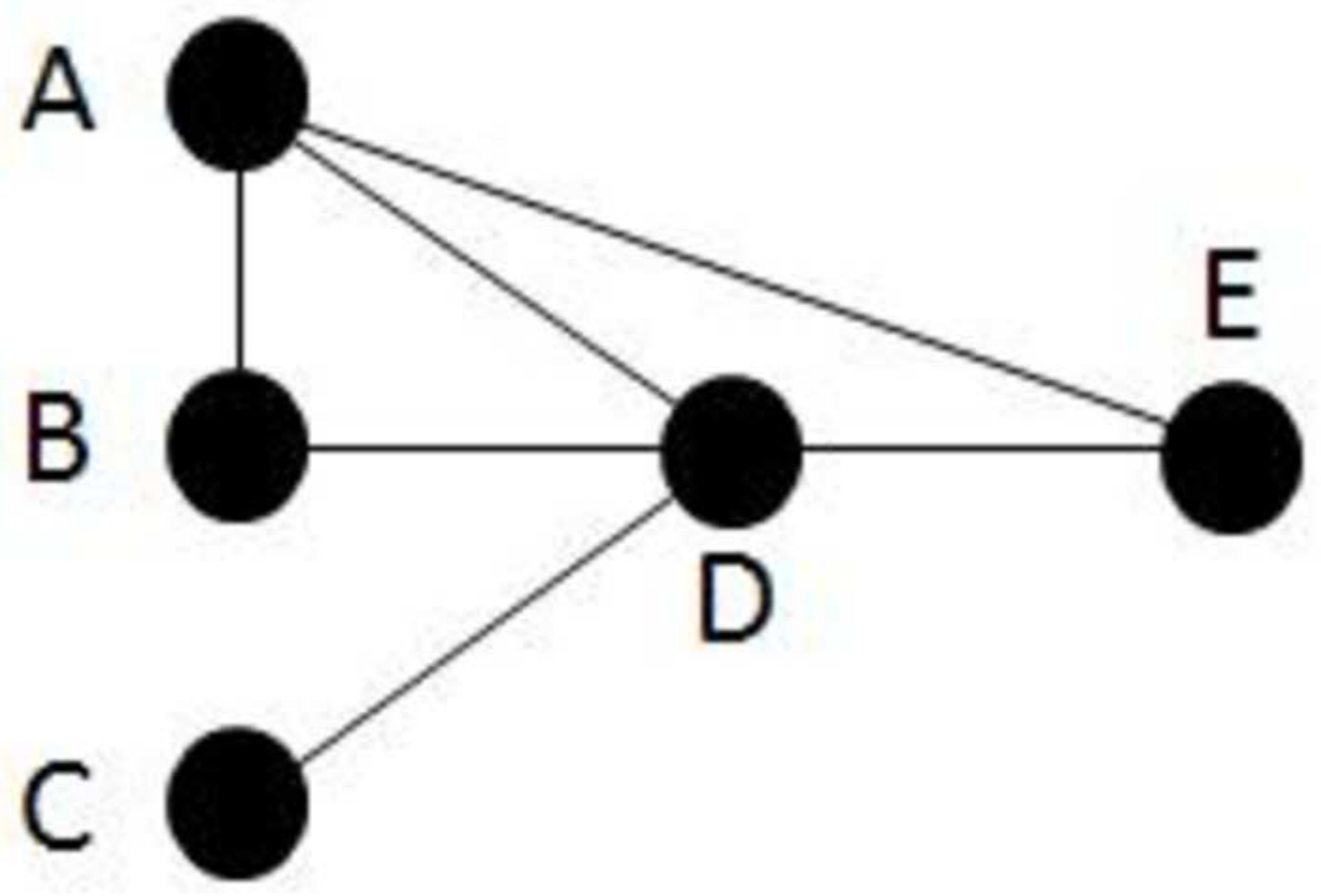




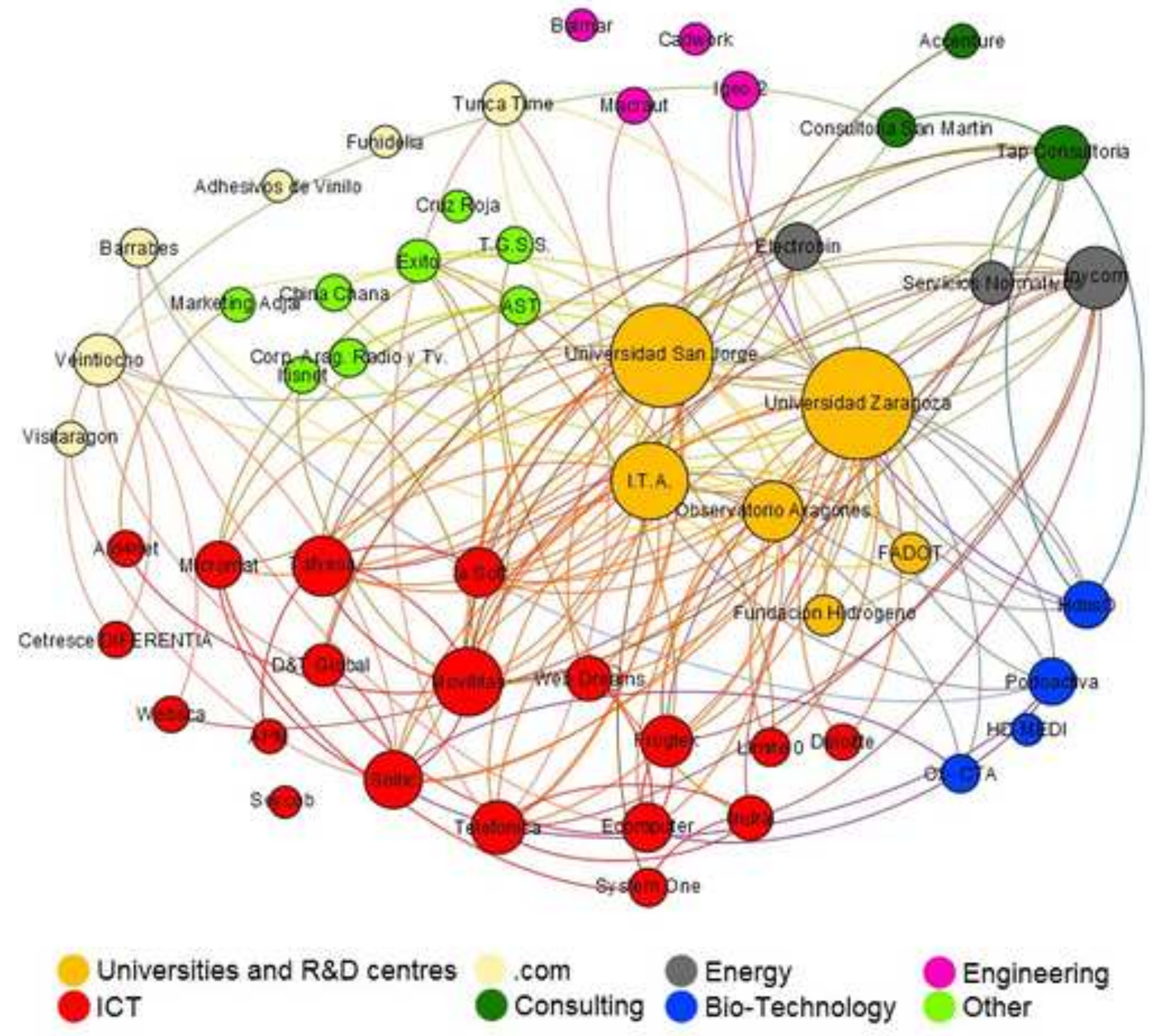




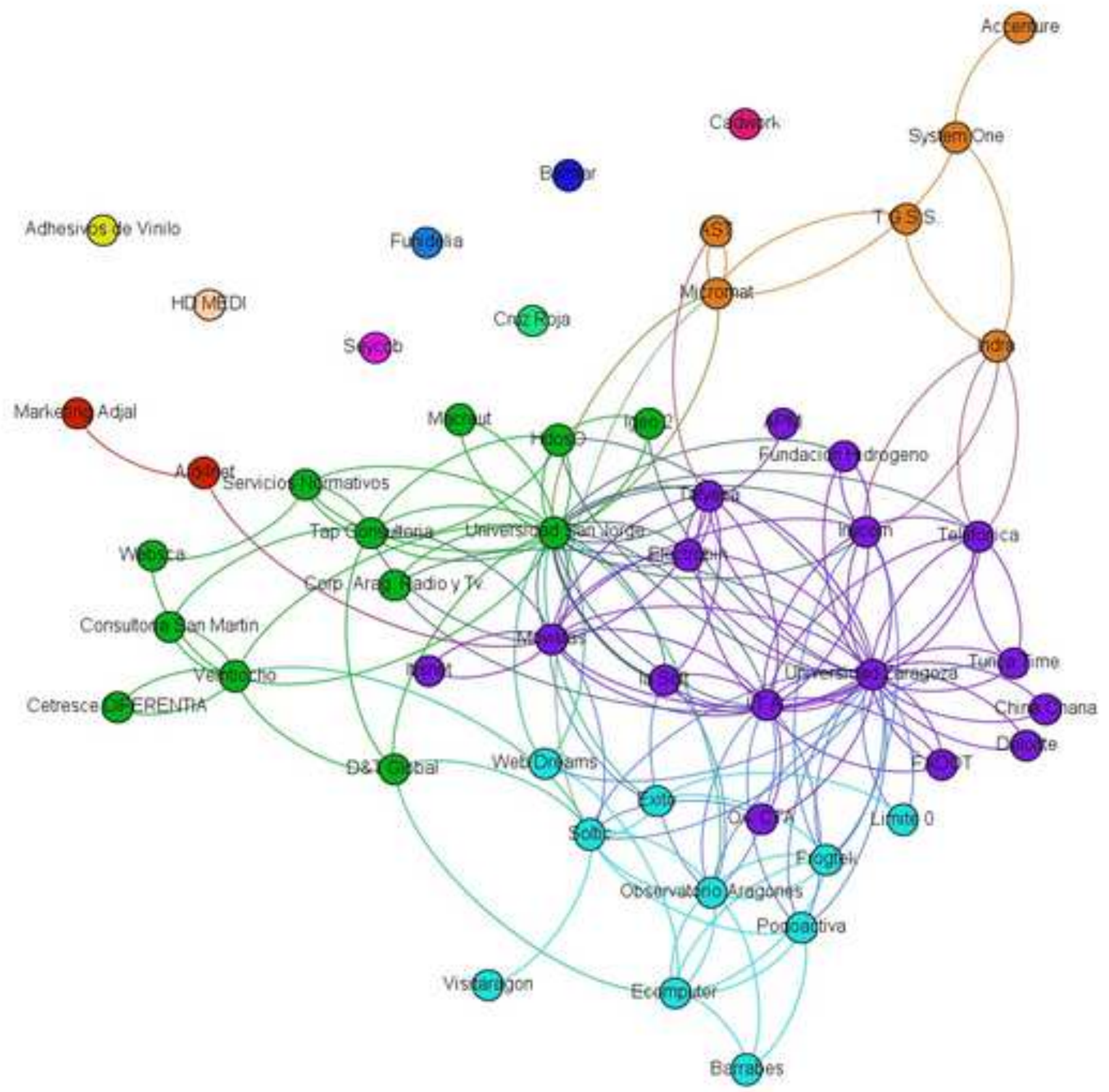


Table 1

Characteristics of the sample

\begin{tabular}{|c|c|c|}
\hline Variable & Descriptor & $\%$ \\
\hline \multicolumn{3}{|c|}{ Position of the respondent: } \\
\hline & Owner & 32 \\
\hline & Managing Director & 19 \\
\hline & R\&D Director & 8 \\
\hline & Other & 41 \\
\hline \multicolumn{3}{|c|}{ Origin of the enterprise: } \\
\hline & Independent external enterprise & 50 \\
\hline & Subsidiary of another larger external corporation & 28 \\
\hline & Start-up & 10 \\
\hline & Other & 12 \\
\hline \multicolumn{3}{|c|}{ Currently, the company is: } \\
\hline & Independent & 59 \\
\hline & A subsidiary with considerable autonomy & 23 \\
\hline & A subsidiary with little autonomy & 12 \\
\hline & Other & 6 \\
\hline \multicolumn{3}{|l|}{ Sector: } \\
\hline & ICT & 35.8 \\
\hline & dot-com & 11.3 \\
\hline & Universities, R\&D Centres & 11.3 \\
\hline & Medicine and Biotechnology & 7.5 \\
\hline & Engineering & 7.5 \\
\hline & Consulting & 5.6 \\
\hline & Energy-Environment & 5.6 \\
\hline \multicolumn{3}{|c|}{ Asset value in 2011: } \\
\hline & $>€ 1,000,000$ & 34 \\
\hline & $€ 500,001-1,000,000$ & 15 \\
\hline & $€ 300,001-500,000$ & 8 \\
\hline & $€ 100,001-300,000$ & 6 \\
\hline & $<€ 100,000$ & 37 \\
\hline \multicolumn{3}{|c|}{ Turnover in 2011: } \\
\hline & $>€ 5,000,000$ & 12 \\
\hline & $€ 1,000,001-5,000,000$ & 16 \\
\hline & $€ 300,001-100,000$ & 18 \\
\hline & $€ 100,001-300,000$ & 20 \\
\hline & $<€ 100,000$ & 34 \\
\hline \multicolumn{3}{|c|}{ Years in the park: } \\
\hline & 10 years & 14 \\
\hline & $5-10$ years & 28 \\
\hline & $1-5$ years & 48 \\
\hline & $<1$ year & 10 \\
\hline
\end{tabular}


Table 2

Results obtained for the Walqa STP

\begin{tabular}{|c|c|c|c|c|c|c|c|}
\hline Id & Sector & $\begin{array}{l}\text { Degree } \\
\text { centrality }\end{array}$ & $\begin{array}{l}\text { Closeness } \\
\text { Centrality }\end{array}$ & $\begin{array}{c}\text { Betweenness } \\
\text { Centrality }\end{array}$ & $\begin{array}{l}\text { Clustering } \\
\text { Coefficient }\end{array}$ & $\begin{array}{l}\text { Eigenvector } \\
\text { Centrality }\end{array}$ & $\begin{array}{c}\text { Modularity } \\
\text { Class }\end{array}$ \\
\hline Accenture & $\mathrm{C}$ & 0,02 & 4,02 & 0,00 & 0,00 & 0,00 & 8 \\
\hline Adhesivos de Vinilo & W & 0,00 & 0,00 & 0,00 & 0,00 & 0,00 & 0 \\
\hline Aid4net & $\mathrm{T}$ & 0,04 & 2,87 & 44,00 & 0,00 & 0,09 & 9 \\
\hline APM & $\mathrm{T}$ & 0,02 & 3,07 & 0,00 & 0,00 & 0,00 & 7 \\
\hline AST & 0 & 0,06 & 2,82 & 4,00 & 0,00 & 0,13 & 8 \\
\hline Balmar & I & 0,00 & 0,00 & 0,00 & 0,00 & 0,00 & 1 \\
\hline Barrabes & W & 0,06 & 2,98 & 0,25 & 0,50 & 0,16 & 10 \\
\hline Cadwork & I & 0,00 & 0,00 & 0,00 & 0,00 & 0,00 & 2 \\
\hline Cetresce DIFERENTIA & $\mathrm{T}$ & 0,04 & 3,24 & 0,00 & 0,00 & 0,03 & 12 \\
\hline China Chana & $\mathrm{O}$ & 0,04 & 2,73 & 0,00 & 0,00 & 0,15 & 6 \\
\hline Consultoria San Martin & $\mathrm{C}$ & 0,06 & 3,07 & 0,67 & 0,00 & 0,03 & 12 \\
\hline Corp. Arag. Radio y Tv. & $\mathrm{O}$ & 0,06 & 2,33 & 0,71 & 0,00 & 0,15 & 7 \\
\hline Cruz Roja & $\mathrm{O}$ & 0,00 & 0,00 & 0,00 & 0,00 & 0,00 & 3 \\
\hline D\&T Global & $\mathrm{T}$ & 0,09 & 2,24 & 15,86 & 0,25 & 0,04 & 12 \\
\hline Deloitte & $\mathrm{T}$ & 0,04 & 2,73 & 0,00 & 0,00 & 0,15 & 6 \\
\hline Ecomputer & $\mathrm{T}$ & 0,15 & 2,73 & 10,06 & 0,13 & 0,24 & 10 \\
\hline Electrobin & $E$ & 0,13 & 2,18 & 0,71 & 0,83 & 0,48 & 7 \\
\hline Exito & $\mathrm{O}$ & 0,09 & 2,24 & 18,71 & 0,15 & 0,00 & 9 \\
\hline FADOT & V & 0,08 & 2,62 & 0,00 & 1,00 & 0,29 & 6 \\
\hline Frogtek & $\mathrm{T}$ & 0,17 & 2,38 & 11,88 & 0,20 & 0,37 & 10 \\
\hline Fundacion Hidrogeno & $\mathrm{V}$ & 0,08 & 2,29 & 0,71 & 0,67 & 0,40 & 6 \\
\hline Funidelia & W & 0,00 & 0,00 & 0,00 & 0,00 & 0,00 & 4 \\
\hline HD MEDI & B & 0,00 & 0,00 & 0,00 & 0,00 & 0,00 & 5 \\
\hline $\mathrm{HdosO}$ & B & 0,13 & 2,27 & 5,95 & 0,33 & 0,35 & 7 \\
\hline I.T.A. & V & 0,40 & 1,96 & 49,41 & 0,28 & 0,94 & 6 \\
\hline la Soft & $\mathrm{T}$ & 0,15 & 2,18 & 3,12 & 0,65 & 0,61 & 7 \\
\hline Igeo 2 & 1 & 0,06 & 2,31 & 0,71 & 0,67 & 0,21 & 7 \\
\hline Indra & $\mathrm{T}$ & 0,11 & 2,78 & 30,13 & 0,08 & 0,20 & 6 \\
\hline Inycom & $E$ & 0,26 & 2,02 & 46,15 & 0,38 & 0,68 & 6 \\
\hline Itisnet & $\mathrm{O}$ & 0,04 & 2,91 & 0,00 & 0,00 & 0,09 & 9 \\
\hline Limite 0 & $\mathrm{~T}$ & 0,06 & 2,62 & 1,04 & 0,00 & 0,15 & 9 \\
\hline Macraut & 1 & 0,04 & 2,64 & 0,00 & 0,00 & 0,15 & 7 \\
\hline Marketing Adjal & $\mathrm{O}$ & 0,02 & 3,84 & 0,00 & 0,00 & 0,02 & 9 \\
\hline Micromat & $\mathrm{T}$ & 0,13 & 2,24 & 108,95 & 0,00 & 0,23 & 8 \\
\hline Movilitas & $\mathrm{T}$ & 0,32 & 1,93 & 153,60 & 0,25 & 0,60 & 9 \\
\hline Observatorio Aragones & V & 0,25 & 2,20 & 43,99 & 0,16 & 0,54 & 10 \\
\hline Ox- CTA & B & 0,06 & 2,36 & 0,40 & 0,67 & 0,36 & 6 \\
\hline Podoactiva & B & 0,13 & 2,27 & 22,61 & 0,25 & 0,29 & 10 \\
\hline Servicios Normativos & $E$ & 0,09 & 2,56 & 14,48 & 0,33 & 0,20 & 12 \\
\hline Seycob & $\mathrm{T}$ & 0,00 & 0,00 & 0,00 & 0,00 & 0,00 & 11 \\
\hline Soltic & $\mathrm{T}$ & 0,23 & 1,91 & 144,11 & 0,08 & 0,41 & 12 \\
\hline System One & $\mathrm{T}$ & 0,06 & 3,04 & 45,40 & 0,00 & 0,00 & 8 \\
\hline
\end{tabular}




\begin{tabular}{lccccccc}
\hline \multicolumn{1}{c}{ Id } & Sector & $\begin{array}{c}\text { Degree } \\
\text { centrality }\end{array}$ & $\begin{array}{c}\text { Closeness } \\
\text { Centrality }\end{array}$ & $\begin{array}{c}\text { Betweenness } \\
\text { Centrality }\end{array}$ & $\begin{array}{c}\text { Clustering } \\
\text { Coefficient }\end{array}$ & $\begin{array}{c}\text { Eigenvector } \\
\text { Centrality }\end{array}$ & $\begin{array}{c}\text { Modularity } \\
\text { Class }\end{array}$ \\
\hline T.G.S.S. & $\mathrm{O}$ & 0,04 & 3,09 & 1,40 & 0,00 & 0,07 & 8 \\
Tafyesa & $\mathrm{T}$ & 0,25 & 2,09 & 72,91 & 0,36 & 0,60 & 7 \\
Tap Consultoria & $\mathrm{C}$ & 0,19 & 2,29 & 31,42 & 0,23 & 0,34 & 12 \\
Telefonica & $\mathrm{T}$ & 0,19 & 2,16 & 28,15 & 0,47 & 0,62 & 6 \\
Tunca Time & $\mathrm{W}$ & 0,09 & 2,47 & 1,62 & 0,33 & 0,33 & 6 \\
Universidad San Jorge & $\mathrm{V}$ & 0,62 & 1,67 & 316,64 & 0,09 & 0,94 & 7 \\
Universidad Zaragoza & $\mathrm{V}$ & 0,70 & 1,76 & 261,97 & 0,08 & 1,00 & 6 \\
Veintiocho & $\mathrm{W}$ & 0,17 & 2,27 & 91,26 & 0,07 & 0,17 & 12 \\
Visitaragon & $\mathrm{W}$ & 0,02 & 2,89 & 0,00 & 0,00 & 0,06 & 12 \\
Web Dreams & $\mathrm{T}$ & 0,11 & 2,27 & 6,79 & 0,00 & 0,35 & 10 \\
Websca & $\mathrm{T}$ & 0,04 & 3,18 & 1,22 & 0,00 & 0,06 & 12 \\
\hline
\end{tabular}

